\title{
A Study of Psychomotor Abilities of Hearing Impaired Children
}

\author{
Mukhtar Ahmad Shah ${ }^{1}$, Anwar Aziz Dar ${ }^{2}$
}

Research Scholar, Department of Physical Education, Choudary Charan Singh University Meeruth, U.P.India

Research Scholar, Dept. of . Physical Education, Dr.C.V. Raman University,

Bilaspur, Chhattisgarh, India

Email:ahmadmukthar16@gmail.com

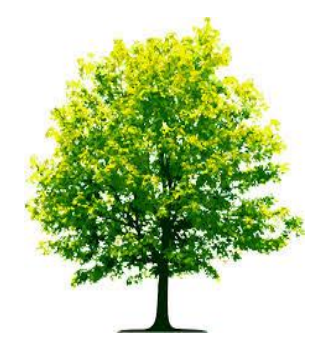

Keywords:

Psychomotor, Hearing, Balance, Visual perception, Differentiation ability, Reaction ability, Kinesthetic Perception,

\begin{abstract}
A B S T R A C T
Present study has been aimed to see the status of psychomotor abilities and psychological variable of hearing impaired children of National capital region. 100 school students from the age group of $14-18$ years were selected. To measure psychomotor abilities and psychological variables like Static balance, dynamic balance, kinesthetic perception, visual perception, reaction time and differentiation ability following equipments were used. Static balance with Strok Stand Test, Dynamic Balance with Bass, Balance Test, Reaction time with Nelson Hand Reaction Timer, Kinesthetic Perception with Kinesthetic Obstacle Test, Visual perception with Muller Lyer Visual Perception apparatus, differentiation Ability with Backward Basketball Throw Test were measured respectively and to measure psychological variable Anxiety with Questionnaire developed by Dr. Anil Kumar was adopted.
\end{abstract}

Citation: Mukhtar Ahmad Shah, Anwar Aziz Dar (2019). A Study of Psychomotor Abilities of Hearing Impaired Children. International Journal of Advanced Multidisciplinary Scientific Research (IJAMSR) ISSN:2581-4281, 2 (1), January, 2019, \# Art.1120, pp 65-71 


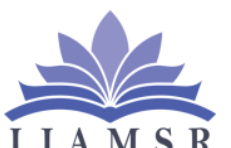

\section{International Journal of Advanced Multidisciplinary Scientific Research (IJAMSR) ISSN:2581-4281}

\section{Introduction}

Psychomotor ability is the ability to perform body motor movements (movement of fingers, hands, legs, etc.) with precision, coordination, or strength. Psychomotor is related to movement or muscular activity associated with mental processes and ability that influence the capacity to manipulate and control objects. Challenged have lack of physical or sensorial ability to adjust to the environment. But still they are fighting with their disabilities and trying their best to come into the mainstream of society. They are proving* themselves in every field whether that is a field of sports, education, service or business. E.g, Hearing loss is a full or partial decrease in the ability to detect or understand sound, Caused by a wide range of biological and environmental factors can happen to any organism that perceives sound. A loss of more than $71 \mathrm{db}$ is considered severely and profoundly hearing Impaired.

\section{Statement of Problem}

The title of the study was stated as "Psychomotor abilities of hearing impaired children".

\section{Objective of The Study}

a) The purpose of this study was to know the psychomotor abilities of hearing impaired children.

b) The purpose of this study was to determine the Psychomotor abilities of hearing impaired children.

\section{Delimitation}

i. The study was delimited to the following selected variables:

a) Visual Perception (b) Static Balance ability (c) Dynamic balance ability (d) Differentiation ability (e) Kinesthetic Perception (f) Reaction time

ii. The study was further delimited to Anxiety as psychological variable.

iii. The study was also delimited to the hearing impaired children.

iv. The age of the subjects ranged from 14-18 years.

v. Total 100 hearing impaired children were selected from the national capital region (NCR). 


\section{Limitation}

Factors, which could not be controlled in the study, were as follows:

a. Environmental factors.

b. Difference regarding subject's daily routine, diet, habits, facilities etc.

c. Non availability of sophisticated tools were accepted as a limitation of the study.

\section{Hypothesis}

Before setting the hypothesis the researcher undergone the related studies in the area of particular subjects and consulted experts in this regards. On the basis of their advice and suggestions and the experience of the research scholar it was hypothesized that:

There will be a significant relationship between psychomotor ability (Static Balance, Dynamic Balance, Reaction Time, Kinesthetic Perception, Differentiation Ability, and Visual Perception) and Anxiety of hearing impaired.

\section{Methodology:}

To find out the status of psychomotor abilities and were taken: psychological variables following methodological steps

\section{Psychological variables:}
a) Anxiety

\section{Selection of Subjects}

To achieve the purpose of the study One hundred hearing impaired children were selected by purposive sampling method from the national capital region (NCR). The ages of the subjects were ranged between 14 to18 years.

The study was taken in identifying the psychomotor abilities of hearing impaired children. On the basis of literature, evidence, expert's opinion and researchers' own understanding the following variables were selected for the purpose of this study.

\section{Psychomotor abilities:}
a) Visual perception
b) Balance ability
c) Differentiation ability
d) kinesthetic perception
e) Reaction time 
International Journal of Advanced Multidisciplinary Scientific Research (IJAMSR) ISSN:2581-4281 Volume 2, Issue 1, January, 2019

IJAMSR 2 (1) Www.ijamsr.com $\quad$ CrossRef: https://doi.org/10.31426/ijamsr.2019.2.1.1120

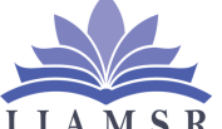

\section{International Journal of Advanced Multidisciplinary Scientific Research (IJAMSR) ISSN:2581-4281}

Statistical Procedure:

Data was collected with the help of questionnaires and apparatus for measuring all psychomotor abilities. To find out the psychomotor abilities of hearing impaired children, descriptive statistics were used. The product moment correlation was used to determine the relationship between Psychomotor abilities and Anxiety of hearing impaired children. The level of significance to check the relationship obtains by Pearson's Product Moment Correlation was set at 0.05 .

Table-1 Psychomotor Abilities of Hearing Impaired Children

\begin{tabular}{|l|r|}
\hline \multicolumn{2}{|c|}{ Static Balance } \\
\hline Mean & 13.49258 \\
\hline Standard Error & 1.202212 \\
\hline Median & 9.97 \\
\hline Mode & 8.47 \\
\hline Standard Deviation & 9.466227 \\
\hline Sample Variance & 89.60945 \\
\hline Kurtosis & 1.972575 \\
\hline Skewness & 1.338883 \\
\hline Range & 41 \\
\hline Minimum & 3.62 \\
\hline Maximum & 44.62 \\
\hline Sum & 836.54 \\
\hline Count & 100 \\
\hline
\end{tabular}

Table - 2 Descriptive Statistics of Dynamic Balance of hearing impaired boys

\begin{tabular}{|l|r|}
\hline \multicolumn{2}{|c|}{ Dynamic Balance } \\
\hline Mean & 66.56452 \\
\hline Standard Error & 1.208033 \\
\hline Median & 66 \\
\hline Mode & 66 \\
\hline Standard Deviation & 9.512065 \\
\hline Sample Variance & 90.47938 \\
\hline Kurtosis & -0.33364 \\
\hline Skewness & -0.3629 \\
\hline Range & 37 \\
\hline Minimum & 45 \\
\hline Maximum & 4127 \\
\hline Sum & 100 \\
\hline Count & \\
\hline
\end{tabular}

Table -3: Descriptive Statistics Of Reaction Time Of Hearing Impaired Boys

\begin{tabular}{|l|r|}
\hline \multicolumn{2}{|c|}{ Reaction time } \\
\hline Mean & 0.063206 \\
\hline Standard Error & 0.003279 \\
\hline Median & 0.061563 \\
\hline Mode & 0.0875 \\
\hline Standard Deviation & 0.025817 \\
\hline Sample Variance & 0.000667 \\
\hline Kurtosis & -0.9306 \\
\hline Skewness & -0.28229 \\
\hline Range & 0.100567 \\
\hline Minimum & 0.001246 \\
\hline Maximum & 0.101813 \\
\hline Sum & 3.918754 \\
\hline Count & 100 \\
\hline
\end{tabular}


International Journal of Advanced Multidisciplinary Scientific Research (IJAMSR) ISSN:2581-4281 Volume 2, Issue 1, January, 2019

IJAMSR 2 (1) WWw.ijamsr.com $\quad$ CrossRef: https://doi.org/10.31426/ijamsr.2019.2.1.1120

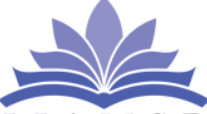

I J A M S R

International Journal of Advanced Multidisciplinary Scientific Research (IJAMSR) ISSN:2581-4281

Table -4: Descriptive Statistics of Differentiation Ability of Hearing Impaired Boys

\begin{tabular}{|l|r|}
\hline \multicolumn{1}{|c|}{ Differentiation Ability } & \\
\hline Mean & 17.12903 \\
\hline Standard Error & 0.219951 \\
\hline Median & 18 \\
\hline Mode & 18 \\
\hline Standard Deviation & 1.731898 \\
\hline Sample Variance & 2.999471 \\
\hline Kurtosis & 1.175352 \\
\hline Skewness & -1.18359 \\
\hline Range & 8 \\
\hline Minimum & 12 \\
\hline Maximum & 20 \\
\hline Sum & 1062 \\
\hline Count & 100 \\
\hline
\end{tabular}

Table - 5 Descriptive Statistics Of Kinesthetic Perception Of Hearing Impaired Boys

\begin{tabular}{|l|r|}
\hline \multicolumn{2}{|c|}{ Kinesthetic Perception } \\
\hline Mean & 30.08065 \\
\hline Standard Error & 2.035811 \\
\hline Median & 25 \\
\hline Mode & 15 \\
\hline Standard Deviation & 16.02999 \\
\hline Sample Variance & 256.9606 \\
\hline Kurtosis & -0.59136 \\
\hline Skewness & 0.688164 \\
\hline Range & 55 \\
\hline Minimum & 10 \\
\hline Maximum & 65 \\
\hline Sum & 1865 \\
\hline Count & 100 \\
\hline
\end{tabular}

Table -6: Descriptive Statistics of Visual Perception of Hearing Impaired Boys

\begin{tabular}{|l|r|}
\hline \multicolumn{2}{|c|}{ Visual Perception } \\
\hline Mean & 0.533629 \\
\hline Standard Error & 0.043346 \\
\hline Median & 0.39 \\
\hline Mode & 0.28 \\
\hline Standard Deviation & 0.341308 \\
\hline Sample Variance & 0.116491 \\
\hline Kurtosis & 0.402758 \\
\hline Skewness & 1.085541 \\
\hline Range & 1.315 \\
\hline Minimum & 0.12 \\
\hline Maximum & 1.435 \\
\hline Sum & 33.085 \\
\hline Count & 100 \\
\hline
\end{tabular}

Table -7: Descriptive Statistics Of Anxiety Of Hearing Impaired Boys

\begin{tabular}{|l|r|}
\hline \multicolumn{1}{|c|}{ Anxiety } & \\
\hline Mean & 28.27419 \\
\hline Standard Error & 0.722154 \\
\hline Median & 30 \\
\hline Mode & 33 \\
\hline Standard Deviation & 5.686248 \\
\hline Sample Variance & 32.33342 \\
\hline Kurtosis & -0.56699 \\
\hline Skewness & -0.63065 \\
\hline Range & 22 \\
\hline Minimum & 16 \\
\hline Maximum & 38 \\
\hline Sum & 1753 \\
\hline Count & 100 \\
\hline
\end{tabular}

Table No. -7 evident that total sum of anxiety 
Table - 8: Relationship Of Selected Psychomotor Abilities To Anxiety

\begin{tabular}{|l|l|}
\hline psychomotor abilities & Correlation coefficient \\
\hline static balance & 0.005877 \\
\hline dynamic balance & 0.084987 \\
\hline reaction time & $0.256694 *$ \\
\hline differentiation ability & 0.054611 \\
\hline kinesthetic perception & 0.228163 \\
\hline visual perception & -0.02983 \\
\hline
\end{tabular}

On the basis of results following conclusion has been drawn.

Table No. - 1 evident that the total sum of Static Balance of hearing impaired boys was 836.54 , and the population was 100, therefore Mean was 13.49258, Median was 9.97, Mode was 8.47, Maximum value was 44.62, Minimum value was 3.62, so Range was 41, Standard deviation was 9.466227, Standard error was 1.202212, Sample Variance was 89.60945, Skewness was 1.33883 and Kurtosis was 1.972575 .

Table No. - 2 evident that the total sum of Dynamic Balance of hearing impaired boys was 4127 and the population was 100 , therefore Mean was 66.56452, Median was 66, Mode was 66, Maximum value was 82, Minimum value was 45 , so Range was 37 , Standard deviation was 9.512065, Standard error was 1.208033, Sample Variance was 90.47938, Skewness was -0.3629 and Kurtosis was -0.33364 .
Table No. -3 evident that the total sum of Reaction time of hearing impaired boys was 3.918754, and the population was 100, therefore Mean was 0.063206, Median was 0.061563, Mode was 0.0875, Maximum value was 0.101813 , Minimum value was 0.001246 , so Range was 0.100567, Standard deviation was 0.025817, Standard error was 0.003279, Sample Variance was 0.000667, Skewness was -0.28229 and Kurtosis was 0.28229 .

Table No. - 4 evident that the total sum of the Differentiation Ability of hearing impaired boys was 1062 and the population was 100, therefore Mean was 17.12903, Median was 18, Mode was 18, Maximum value was 20 , Minimum value was 12 , so Range was 8 , Standard deviation was 1.731898, Standard Error was 0.219951, Sample Variance was 2.999471, Skewness was -1.18359 and Kurtosis was 1.175352 .

Table No. -5 evident that the total sum of kinesthetic perception of hearing impaired boys was 1865, and the population was 100, therefore Mean was 30.08065, Median was 25, Mode was 15, Maximum value was 65, Minimum value was 10 , so Range was 55, Standard deviation was 16.02999, Standard Error was 2.035811, Sample Variance was 256.9606, Skewness was 0.688164 and Kurtosis was -0.59136 . 


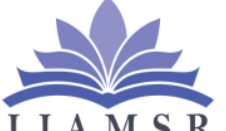

\section{International Journal of Advanced Multidisciplinary Scientific Research (IJAMSR) ISSN:2581-4281}

Table No. - 6 evident that the total sum of visual perception of hearing impaired boys was 33.085 and the population was 100 , therefore Mean was 0.533629 , Median was 0.39, Mode was.28, Maximum value was 1.435, Minimum value was 0.12 , so Range was 1.315 , Standard deviation was 0.341308, Standard Error was 0.043346, Sample Variance was 0.116491, Skewness was 1.085541 and Kurtosis was 0.402758 .

Table No. -7 evident that the total sum of anxiety of hearing impaired boys was 1753 and the population was 100, therefore Mean was 28.27419, Median was 30, Mode was 33, Maximum value was 38, Minimum value was 16, so Range was 22, Standard deviation was 5.686248, Standard Error was 0.722154, Sample Variance was 32.33342, Skewness was -0.63065 and Kurtosis was -0.56699 .

r" needed for significant at 0.05 level with df $61=.25$ (for two tailed test)

Table No 8, evident that calculated value is 0.005877 for static balance, 0.084987 for dynamic balance, 0.054611 for differentiation ability, 0.228163 for kinesthetic perception, -0.02983 for visual perception which was less than tabulated value .25 , So it was clearly indicated that there were no significance relationship between psychomotor ability(static balance, dynamic balance, differentiation ability, kinesthetic perception, visual perception) and anxiety but calculated value of reaction time was 0.256694 , which was greater than tabulated value .25 , it was clearly indicated that there was significance relationship between reaction time and anxiety of hearing impaired boys.

\section{References}

1) Agrawal J. C., "Teacher and Education in Developing Society", Dehli Vikas publishing house, 1998.

2) Bucher Charles. A, "Foundation of Physical Education and Sports", London: The C.V. Mos Company, 1986.

3) Carle Will. Goose, "The Curriculam in Physical Education”, Vikash publisher, New delhi, 1979.

4) D.P. Hallahn and J.M. Kauffmen, "Exceptional Children" (5 ${ }^{\text {th }}$ ed.), Boston; Allyn and bacon, 1991.

5) David A., Jean P.,Carol H., "Principal and Methods of Adopted Physical Education", McGraw-Hill, 2001.

6) David H. Clarke, "Research Processes in Physical Education", Prentice-Hall, Inc.,Englewood Cliffs, 1984.

7) Devender K.Kensal , "Applied Measurement Education and Sports Selection" , D.V.S. Publication, 1996.

8) Hardyal Singh , "Science of Sports Training" ,D.V.S. Publication, 1993. D.V.S. Publication.1993.

9) Joseph P. Winnick, "Adopted Physical Education and Sports”, New York: Macmillan publishing co, 2006. 